\title{
Clinically Relevant Effect of a New Intranasal Therapy (MP29-02) in Allergic Rhinitis Assessed by Responder Analysis
}

\author{
Eli Meltzer ${ }^{a}$ Paul Ratner ${ }^{c}$ Claus Bachert ${ }^{\mathrm{g}}$ Warner Carr $^{\mathrm{b}}$ William Berger ${ }^{\mathrm{b}}$ \\ G. Walter Canonica ${ }^{\text {h }}$ James Hadley ${ }^{e}$ Phil Lieberman ${ }^{f}$ Frank C. Hampel ${ }^{d}$ \\ Joaquim Mulloli Ullrich Munzel $^{j}$ David Price $^{m}$ Glenis Scadding ${ }^{n}$ \\ J. Christian Virchow ${ }^{k}$ Ulrich Wahn' ${ }^{\prime}$ Ruth Murray ${ }^{\circ}$ Jean Bousquet ${ }^{p}$
}

${ }^{a}$ Allergy and Asthma Medical Group and Research Center, San Diego, Calif., ${ }^{b}$ Allergy and Asthma Associates of Southern

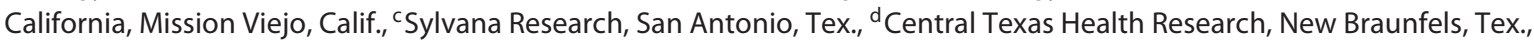
e University of Rochester Medical Center, Rochester, N.Y., fUniversity of Tennessee College of Medicine, Memphis, Tenn., USA;

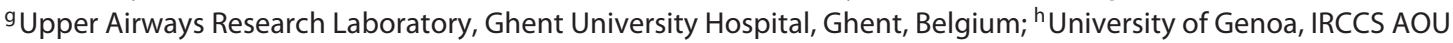
S. Martino, Genoa, Italy; 'Hospital Clínic, IDIBAPS, CIBERES, Barcelona, Spain; ' MEDA Pharma GmbH \& Co. KG, Bad Homburg, kUniversity Hospital, Rostock, and 'Children's Hospital Charité, Berlin, Germany; ${ }^{\mathrm{m}}$ University of Aberdeen, Aberdeen, and ${ }^{n}$ The Royal National Throat, Nose and Ear Hospital, London, UK; ${ }^{\circ}$ MedScript, Dundalk, Ireland; ${ }^{P}$ Arnaud de Villeneuve University Hospital, Montpellier and Inserm CESP1018, Montpellier, France

\section{Key Words}

Allergic rhinitis · Azelastine · Fluticasone $\cdot$ MP29-02 ·

Responder analysis · Severe chronic upper airway disease

\begin{abstract}
Background: It is unclear what constitutes a clinically meaningful response for allergic rhinitis (AR) outcomes. The objectives of these post hoc analyses were (1) to define a clinically meaningful response using novel efficacy analyses (including a responder analysis), and (2) to compare the efficacy of MP29-02 [a novel intranasal formulation of azelastine hydrochloride (AZE) and fluticasone propionate (FP)] with commercially available FP, AZE and placebo in seasonal AR (SAR) patients, using these novel analyses. Methods: 610 moderate-to-severe SAR patients ( $\geq 12$ years old) were randomized into a double-blind, placebo-controlled, 14-day, parallelgroup trial. Change from baseline in the reflective total nasal symptom score (rTNSS) over 14 days was the primary outcome. Post hoc endpoints included the sum of nasal and oc-
\end{abstract}

ular symptoms (rT7SS), efficacy by disease severity and by predominant nasal symptom, and a set of responder analyses. Results: MP29-02 most effectively reduced rT7SS (relative greater improvement: $52 \%$ to FP; $56 \%$ to AZE) and both nasal and ocular symptoms irrespective of severity. More MP29-02 patients achieved $\mathrm{a} \geq 30, \geq 50, \geq 60, \geq 75$ and $\geq 90 \%$ rTNSS reduction, which occurred days faster than with either active comparator; MP29-02 alone was superior to placebo at the $\geq 60 \%$ (or higher) threshold. One in 2 MP29-02 patients achieved $\mathrm{a} \geq 50 \%$ rTNSS reduction and 1 in 6 achieved complete/near-to-complete response. Only MP29-02 was consistently superior to placebo for all patients, whatever their predominant symptom. Conclusions: MP29-02 provided faster and more complete symptom control than first-line therapies. It was consistently superior irrespective of severity, response criteria or patient-type, and may be considered the drug of choice for moderate-to-severe AR. These measures define a new standard for assessing relevance in AR.

Copyright $\odot 2013$ S. Karger AG, Basel

\begin{tabular}{ll}
\hline KARGER & ( 2013 S. Karger AG, Basel \\
& $1018-2438 / 13 / 1614-0369 \$ 38.00 / 0 \quad$ Karger \\
E-Mail karger@karger.com & $\begin{array}{l}\text { This is an Open Access article licensed under the terms } \\
\text { of the Creative Commons Attribution-NonCommercial- } \\
\text { www.karger.com/iaa }\end{array}$ \\
$\begin{array}{l}\text { NoDerivs 3.0 License (www.karger.com/OA-license), appli- } \\
\text { cable to the online version of the article only. Distribution } \\
\text { for non-commercial purposes only. }\end{array}$
\end{tabular}

Correspondence to: Prof. Jean Bousquet

Arnaud de Villeneuve University Hospital and Inserm CSP1018

FR-34059 Montpellier (France)

E-Mail jean.bousquet@orange.fr 


\section{Introduction}

The treatment of allergic rhinitis (AR) is well defined [1]. Most patients seen by physicians present with moderate/severe disease $[2,3]$. Treatment-resistant phenotypes (e.g. severe chronic upper airways disease) have been described $[4,5]$ in around $20 \%$ of treated patients. AR impacts on quality of life [6-8] and is costly [9]. Any treatment providing substantial or near-to-complete symptom relief will have a considerable socioeconomic impact.

Intranasal corticosteroids (INS) are the most effective monotherapy for AR $[1,10,11]$, but many patients are dissatisfied with treatment [12] and experience breakthrough symptoms [2,3], and consequently most patients are seeking a new medication [13]. Nasal obstruction and ocular symptoms represent the most bothersome symptoms [14, $15]$ and are often difficult to control. Most physicians treat patients using multiple therapies $[2,3,16,17]$ to achieve quicker and more profound symptom relief [18], despite limited evidence to support this practice $[10,11]$.

Statistical significance over placebo is a proof of clinical efficacy. However, clinical relevance is more difficult to judge, particularly when comparing active therapies, and cannot be expressed by a single endpoint or analysis. Rather, clinical relevance is influenced by patient-related factors such as disease severity, the predominant symptom and conjunctivitis, and may be better expressed in terms of (1) the level of response (e.g. substantial or complete); (2) the time to achieve it; (3) an assessment of efficacy in treating the entire AR symptom complex, and (4) efficacy assessment irrespective of disease severity or the predominant symptom.

\section{Background and Objectives}

\section{Scientific Background and Explanation of Rationale}

Clinical trials should demonstrate a statistically significant improvement in the primary efficacy endpoint, but clinical relevance is not readily apparent from this analysis. One approach is to conduct a responder analysis [19] described in regulatory guidelines $[20,21]$ to define a level of response not achievable with available first-line therapy.

MP29-02, a novel intranasal formulation of azelastine hydrochloride (AZE) and fluticasone propionate (FP), has previously been shown to be more effective than INS $[22,23]$. We have taken the first of these studies, which compared MP29-02 to commercially available active comparators (i.e. Astelin ${ }^{\circledR}$ and generic Flonase ${ }^{\circledR}$ ) [22] to assess the data in a more clinically relevant way using sev- eral new analyses. Many of these analyses had not previously been developed at the time of study protocol submission and so were introduced post hoc.

\section{Specific Objectives}

This is a post hoc analysis of a phase III, multicenter, randomized, double-blind, parallel group trial [MP4001 (NCT00660517)] [22]. The aim was to firstly introduce new and more clinically meaningful efficacy analyses to gauge the efficacy of AR therapies, and secondly to assess the efficacy of MP29-02 and currently available first-line AR therapies using these new analyses. Specifically, this article investigates whether MP29-02 is more effective than commercially available active comparators (intranasal AZE, Astelin; Meda Pharmaceuticals, Somerset, N.J., USA), generic FP nasal spray (Roxane Laboratories, Columbus, Ohio, USA) and placebo in controlling overall nasal and ocular symptoms, irrespective of baseline severity and in those presenting with a predominant symptom. A responder sensitivity analysis defined a level of response not achievable with available first-line therapy. These post hoc parameters were defined a priori by an independent panel of experts (including J.B., W.C., C.B., D.P. and others), without having access to the data. The methods of the study have been previously published [22] and are presented in the online supplementary material (for all online supplementary material, see www.karger.com/doi/10.1159/000351404).

\section{Material and Methods}

\section{Participants}

Subjects ( $\geq 12$ years old) with moderate-to-severe seasonal AR (SAR), with a minimum 2-year history, current rhinitis symptomatology, a positive skin prick test to mountain cedar pollen and who met all the study inclusion/exclusion criteria were randomized.

\section{Planned Interventions and Timing}

The study comprised a 7-day, single-blind, placebo lead-in period, and a 14-day treatment period with 3 study visits on days 1,7 and 14 . On visit 2 (day 1 ), eligible patients were randomized (1:1:1:1) to 14 days of treatment with (1) MP29-02 nasal spray [a novel intranasal formulation of AZE $(137 \mu \mathrm{g})$ and FP $(50 \mu \mathrm{g})]$; (2) commercially available AZE nasal spray $(137 \mu \mathrm{g})$; (3) commercially available FP $(50 \mu \mathrm{g})$ nasal spray, or (4) vehicle placebo nasal spray. All sprays were given as 1 spray/nostril bid. Patients recorded symptom scores in a diary and concordance with treatment was assessed.

\section{Efficacy Variables}

The primary efficacy variable was change from baseline in morning and evening reflective total nasal symptom score 
(rTNSS). Secondary endpoints included change from baseline in reflective total ocular symptom score (rTOSS), individual nasal and ocular symptom scores and the overall score from the 28 -item Rhinitis Quality of Life Questionnaire (RQLQ; online suppl. text) [24].

\section{Sample Size, Randomization and Blinding}

Details on sample size, randomization and blinding are presented in the online supplementary text.

\section{Statistical Analyses}

Both rTNSS and rTOSS were assessed by patient severity using a baseline-adjusted analysis of covariance (ANCOVA) model (online suppl. text). Patients were categorized into two severity groups according to median baseline rTNSS (i.e. $\leq 18.9$ or $>18.9$ ) and overall RQLQ score (i.e. $\leq 3.9$ or $>3.9$ ). Those with a median baseline $\mathrm{rTNSS} \leq 18.9$ or an overall RQLQ score $\leq 3.9$ were defined as less severe. Those patients with a median baseline rTNSS $>18.9$ or an overall RQLQ score $>3.9$ were defined as more severe. This analysis is pertinent since it is important to show efficacy in patients irrespective of symptom severity. A symptomatic subgroup of patients was defined with rTOSS baseline $\geq 8$ to define patients with at least moderate ocular symptoms, since ocular symptoms are often not quantified even though they affect most subjects with SAR [25]. A reflective total of 5 symptom scores (rT5SS; rTNSS plus ocular itching) and a reflective total of 7 symptom scores (rT7SS; rTNSS plus rTOSS) were also determined, and change from baseline was assessed by the same ANCOVA model, as patients frequently present to clinic with both nasal and ocular symptoms.

Time to response in nasal symptoms was analyzed by KaplanMeier estimates and log-rank tests. A change from baseline in morning and evening rTNSS of at least (1) 30, 50 [20], 60, 75 or $90 \%$ and $(2) \leq 1$ point remaining for each symptom score (i.e. complete/near-to-complete symptom resolution for both rTNSS and rT7SS) were used to define response. A $\geq 50 \%$ rTNSS response was considered a substantial response, halving the patient's nasal symptom burden. Accordingly, an $\mathrm{rTNSS} \geq 75 \%$ response was considered an extensive response representing a symptom severity shift in our patients from moderate/severe to mild or less. The $\leq 1$ point score remaining for each symptom score of the rTNSS or rT7SS ensured complete/near-to-complete symptom relief from all nasal symptoms (i.e. rTNSS) or all nasal plus ocular symptoms (i.e. rT7SS). This criterion is extremely strict as it required that each nasal or each nasal plus ocular symptom was categorized as of less than mild severity, meaning that patients would effectively feel symptom free. These responder sensitivity analyses were conceived in response to the EMA guideline (CHMP/EWP/2455/02) which questions the clinical relevance of a simple change from baseline in rTNSS and suggests a clinically meaningful response in symptom score [20].

Patients were characterized by predominant symptoms based on the maximum individual symptom scores at baseline (i.e. congestion, itching, rhinorrhea or sneezing). rTNSS and individual symptom reduction were assessed in patients categorized by their predominant symptom to show control of the entire disease symptom complex in these patients and to show relief of a patient's particular predominant symptom. An analysis of efficacy according to symptom predominance is clinically relevant since patients frequently present with a specific and most bothersome symptom.

Responder Analysis in the Treatment of Allergic Rhinitis

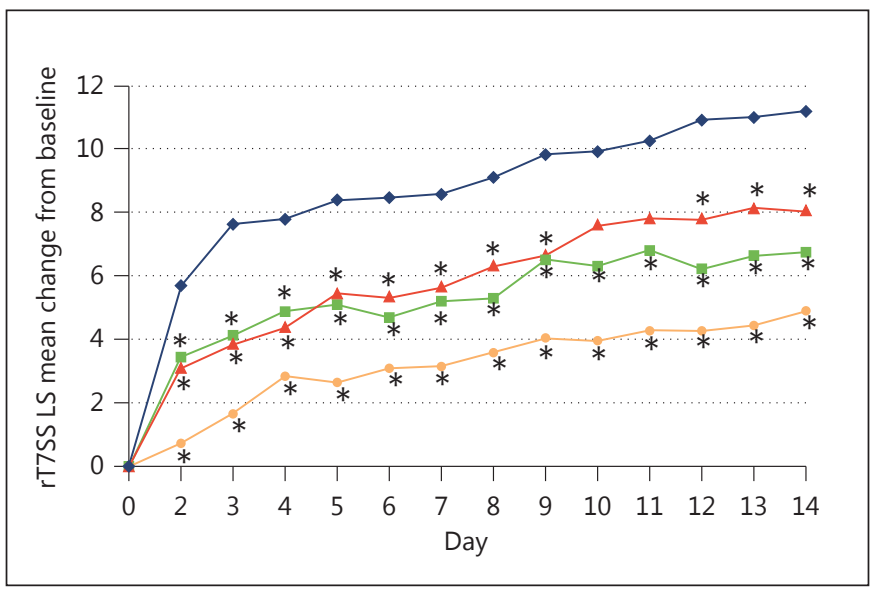

Fig. 1. Effect of MP29-02 (blue), FP (red), AZE (green) and placebo (yellow) on least squares (LS) mean change from baseline in rT7SS by treatment day (numbers and baseline data are provided in online suppl. table 6$) .{ }^{*} \mathrm{p} \leq 0.0336$ vs. MP29-02.

\section{Results}

\section{Patients}

The study was conducted during the 2007-2008 Texas mountain cedar allergy season at 8 investigational sites. Six hundred and ten patients were randomized, and 607 were included in the intend-to-treat population; $94.6 \%$ of patients completed the study. Completion rates were similar across all treatment groups (online suppl. table 1). Baseline characteristics of the four treatment groups were similar (online suppl. table 2) and confirmed that the vast majority of these patients had moderate-tosevere AR.

\section{Outcomes}

\section{Original Analysis}

MP29-02-treated patients experienced a significantly greater reduction in rTNSS (online suppl. fig. 1,2), rTOSS and individual symptom scores compared to FP or AZE (online suppl. tables 3, 4). All active treatments were well tolerated (online suppl. table 5).

\section{Post hoc Analyses}

Rhinoconjunctivitis Symptoms (rT5SS and rT7SS)

MP29-02 patients had a significantly greater reduction in rT5SS and rT7SS than those treated with FP or AZE 
Table 1. rTNSS response sensitivity analysis showing the proportion of patients achieving each response (at day 14) and the advantage (in days) of MP29-02 over active comparators and placebo

\begin{tabular}{|c|c|c|c|c|}
\hline Response criteria $^{1}$ & MP29-02 & AZE & $\mathrm{FP}$ & Placebo \\
\hline \multicolumn{5}{|l|}{$\geq 30 \%$ reduction in $\mathrm{rTNSS}$} \\
\hline Patients at day $14, \%$ & 71.2 & 65.5 & 61.1 & 47.2 \\
\hline \multicolumn{5}{|l|}{$\geq 50$ reduction in $r$ TNSS } \\
\hline Patients at day $14, \%$ & 49.1 & 37.4 & 38.2 & 28.3 \\
\hline Advantage of MP29-02, days & & $\leq 6(p=0.0223)$ & $\leq 6(p=0.0284)^{*}$ & $\leq 10(\mathrm{p}<0.0001)$ \\
\hline Patients at day $14, \%$ & 35.6 & 26.0 & 25.1 & 20.9 \\
\hline Advantage of MP29-02, days & & $\leq 8(p=0.0404)$ & $\leq 7(p=0.0496)$ & $\leq 10(\mathrm{p}=0.0029)$ \\
\hline \multicolumn{5}{|l|}{$\geq 75 \%$ reduction in rTNSS } \\
\hline Patients at day $14, \%$ & 25.5 & 16.4 & 17.7 & 12.9 \\
\hline Advantage of MP29-02, days & & $\leq 8(p=0.0242)$ & $\leq 7(p=0.0848)$ & $\leq 9(\mathrm{p}=0.0032)$ \\
\hline \multicolumn{5}{|l|}{$\geq 90 \%$ reduction in rTNSS } \\
\hline
\end{tabular}

Bold data represent significance vs. placebo. ${ }^{*} \mathrm{p}<0.05$ vs. placebo derived by log-rank tests. Significance values provided are vs. MP29-02. Data in italics denote significance vs. placebo where lost.

${ }^{1}$ Derived by Kaplan-Meier curves estimating time to first response and considering censored data; days advantage refer to the maximal horizontal distances in the Kaplan-Meier curves.

monotherapies (online suppl. table 6). For rT7SS there was a relative greater improvement of 52 and $56 \%$ compared to FP ( $\mathrm{p}=0.0013)$ and AZE $(\mathrm{p}=0.0004)$, respectively. The benefit was observed during the first day of treatment and was sustained over the entire course of treatment (fig. 1).

Reflective Total Nasal Symptom Score Change from Baseline Considering Severity

MP29-02 was significantly superior to both FP and AZE in alleviating patients' overall nasal symptoms regardless of disease severity (online suppl. table 6). For patients with less severe disease (median baseline rTNSS $\leq 18.9$ ) the relative difference with MP29-02 was $42 \%$ compared to FP $(\mathrm{p}=0.0188)$ and $64 \%$ compared to AZE $(\mathrm{p}=0.0002)$, which increased to $49 \%(\mathrm{p}=0.0436)$ and $70 \%(\mathrm{p}=0.0035)$, respectively, for those with more severe disease (median baseline rTNSS >18.9; online suppl. fig. 3).

Reflective Total Ocular Score Change from Baseline Considering Severity

In patients with moderate-to-severe ocular symptoms at baseline (i.e. those with a median baseline rTOSS $\geq 8$ ), MP29-02 was significantly superior to both FP and AZE, with a relative difference of $63 \%$ versus $\mathrm{FP}$ and $42 \%$ versus AZE ( $p=0.0012$ and $p=0.0456$; online suppl. table 6; online suppl. fig. 3 ).

\section{rTNSS Responder Analyses}

For all response cutoffs (i.e. $\geq 30, \geq 50, \geq 60, \geq 75$ and $\geq 90 \%$ response), more MP29-02 patients achieved these rTNSS reductions and did so days faster than both active comparators and placebo patients (table 1; fig. 2). The fraction of responders decreased when stricter response criteria were chosen, but the respective differences between MP29-02 and active comparators became more apparent (table 1). For the $\geq 60, \geq 75$ and $\geq 90 \%$ rTNSS reduction only MP29-02 could be statistically differentiated from placebo (table 1; fig. 2).

For the criterion of $\leq 1$ point remaining in each nasal symptom score, $17.8 \%$ (or 1 in 6) of MP29-02 patients had a complete/near-to-complete nasal symptom resolution versus $9.2 \%$ of FP patients, $8.3 \%$ of AZE patients and $7.8 \%$ of placebo patients (fig. 2). MP29-02 patients achieved this response up to 8 days faster than either FP $(\mathrm{p}=0.0262)$ or placebo $(\mathrm{p}=0.0094)$ and up to 7 days faster than AZE $(p=0.0152)$. For the strictest response criterion of $\leq 1$ point remaining for all symptoms (rT7SS), $14.2 \%$ (or 1 in 7 ) of MP29-02 patients achieved complete/ 


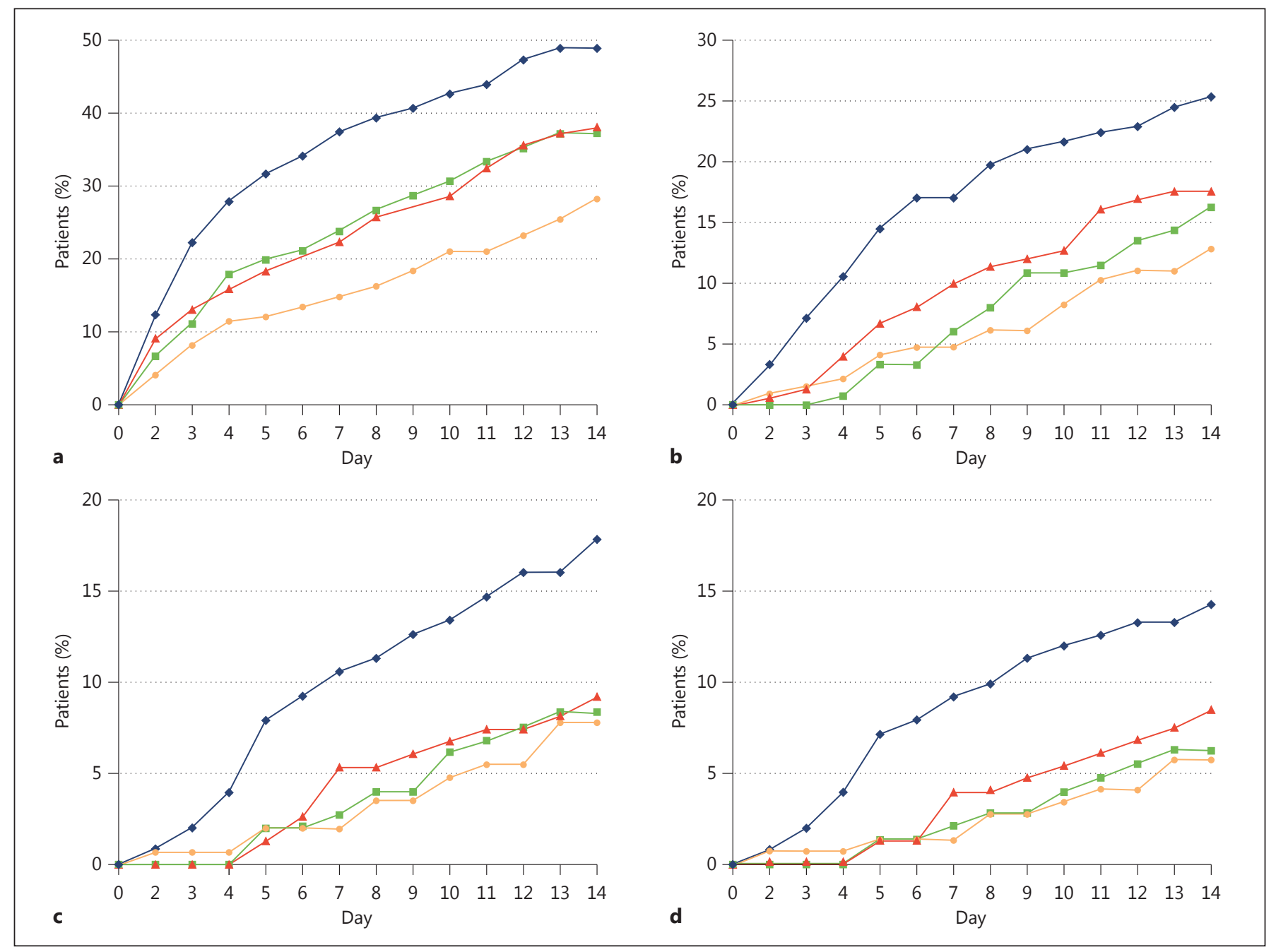

Fig. 2. Time to response curves following treatment for 14 days with MP29-02 (blue), FP (red), AZE (green) and placebo (yellow). a 50\% response. b $75 \%$ response. c rTNSS: $\leq 1$ point remaining for each symptom. d rT7SS: $\leq 1$ point remaining for each symptom.

near-to-complete elimination from all their nasal and ocular symptoms compared to $8.5 \%$ of FP patients, $6.2 \%$ of AZE patients and $5.7 \%$ of placebo patients, achieving this response up to 8 days faster than patients in the FP ( $\mathrm{p}=$ $0.0929)$, AZE ( $\mathrm{p}=0.0204)$ or placebo groups $(\mathrm{p}=0.0123$; fig. 2).

\section{Predominant Symptom}

Only MP29-02 was consistently statistically superior to placebo in reducing rTNSS for all patient types, whatever their leading symptom (table 2). FP was no better than placebo in reducing rTNSS for patients whose predominant symptom was nasal itching (table 2). Compared to FP, MP29-02 provided significantly better $r$ TNSS reduction for those patients mainly suffering from congestion (online suppl. fig. 4), nasal itching or sneezing. Compared to AZE, MP29-02 provided superior rTNSS reduction in those patients for whom congestion (online suppl. fig. 4) and rhinorrhea were the primary complaint.

Only MP29-02 consistently and significantly reduced the individual nasal symptom score compared to placebo corresponding to patients' predominant symptom (with the exception of nasal itching; $\mathrm{p}=0.0657$; table 3 ). By comparison, FP was no more effective than placebo in alleviating nasal congestion or nasal itching in patients presenting with these symptoms predominantly. MP29-02 was significantly superior to FP in relieving nasal congestion (online suppl. fig. 4), itching and sneezing in patients 
Table 2. Reduction in overall nasal symptom score (rTNSS) by patient type

\begin{tabular}{|c|c|c|c|c|c|c|c|}
\hline \multicolumn{8}{|c|}{ rTNSS change from baseline in those patients whose predominant symptom is nasal congestion } \\
\hline MP29-02 $(n=98)$ & $19.56(2.89)$ & -5.64 & - & - & - & - & - \\
\hline $\mathrm{FP}(\mathrm{n}=84)$ & $18.57(3.95)$ & -3.93 & $57 \%$ & MP-FP & -1.71 & $-3.00,-0.43$ & 0.0093 \\
\hline $\mathrm{AZE}(\mathrm{n}=93)$ & $18.20(3.87)$ & -3.28 & $79 \%$ & MP-AZE & -2.36 & $-3.51,-1.21$ & $<0.0001$ \\
\hline \multicolumn{8}{|c|}{ rTNSS change from baseline in those patients whose predominant symptom is nasal itching } \\
\hline MP29-02 $(\mathrm{n}=40)$ & $20.09(3.36)$ & -5.48 & - & - & - & - & - \\
\hline $\mathrm{FP}(\mathrm{n}=45)$ & $20.56(3.06)$ & -3.01 & $100 \%$ & MP-FP & -2.47 & $-4.24,-0.69$ & 0.0072 \\
\hline $\mathrm{AZE}(\mathrm{n}=45)$ & $18.83(3.77)$ & -3.80 & $68 \%$ & MP-AZE & -1.68 & $-3.55,0.19$ & 0.0781 \\
\hline PLA $(n=46)$ & $20.63(3.26)$ & -3.02 & - & MP-PLA & -2.46 & $-4.27,-0.64$ & 0.0088 \\
\hline $\mathrm{FP}(\mathrm{n}=45)$ & $19.50(3.43)$ & -4.89 & $17 \%$ & MP-FP & -0.57 & $-2.31,1.16$ & 0.5131 \\
\hline $\mathrm{AZE}(\mathrm{n}=38)$ & $19.89(3.60)$ & -3.65 & $55 \%$ & MP-AZE & -1.81 & $-3.44,-0.19$ & 0.0294 \\
\hline \multirow[t]{3}{*}{$\operatorname{PLA}(\mathrm{n}=40)$} & $19.91(3.72)$ & -2.19 & - & MP-PLA & -3.27 & $-4.89,-1.65$ & 0.0001 \\
\hline & & & & FP-PLA & -2.70 & $-4.30,-1.11$ & 0.0011 \\
\hline & & & & AZE-PLA & -1.46 & $-2.89,-0.03$ & 0.0456 \\
\hline \multicolumn{8}{|c|}{ rTNSS change from baseline in those patients whose predominant symptom is sneezing } \\
\hline MP29-02 $(\mathrm{n}=25)$ & $19.36(4.19)$ & -5.21 & - & - & - & - & - \\
\hline $\mathrm{FP}(\mathrm{n}=27)$ & $19.59(4.06)$ & -2.96 & $51 \%$ & MP-FP & -2.25 & $-4.05,-0.44$ & 0.0154 \\
\hline $\mathrm{AZE}(\mathrm{n}=22)$ & $20.38(3.52)$ & -4.46 & $17 \%$ & MP-AZE & -0.75 & $-2.66,1.17$ & 0.4401 \\
\hline \multirow[t]{3}{*}{$\operatorname{PLA}(\mathrm{n}=24)$} & $20.35(3.78)$ & -0.84 & - & MP-PLA & -4.37 & $-6.12,-2.62$ & $<0.0001$ \\
\hline & & & & FP-PLA & -2.12 & $-3.85,-0.40$ & 0.0167 \\
\hline & & & & AZE-PLA & -3.62 & $-5.34,-1.91$ & $<0.0001$ \\
\hline
\end{tabular}

PLA = Placebo; $\mathrm{LS}=$ least squares $\mathrm{CFB}=$ change from baseline; $\mathrm{CI}=$ confidence interval.

${ }^{1}$ Mean (SD); maximum baseline rTNSS $=24$.

$2[1-($ FP or AZE - PLA $) /($ MP29-02 - PLA $)] \times 100$.

for whom these were the predominant symptoms. MP2902 was also superior to AZE in relieving congestion (online suppl. fig. 4) and rhinorrhea in patients most bothered by these symptoms (table 3 ).

\section{Discussion}

MP29-02, a novel intranasal formulation of AZE and $\mathrm{FP}$, is more effective than commercially available active comparators in providing relief from all symptoms, including ocular ones. The responder sensitivity analysis showed that more MP29-02 patients achieved each and every response threshold and did so days faster than intranasal FP or AZE, an important consideration since a typical moderate-to-severe SAR episode lasts 12.5 days on average [18]. MP29-02 also provided the greatest relief, irrespective of disease severity, most effectively treated the entire nasal and ocular symptom complex, and targeted patients' most bothersome symptoms.

In this paper we define several new analyses which permit assessment of clinical relevance of treatments for the first time in AR. Regulatory authorities suggest measuring response to treatment using a responder analysis to demonstrate the magnitude of clinical effect $[20,21]$, but they are seldom reported. Here we assess clinically relevant response using novel time to response sensitivity analyses which included both relative and absolute response criteria. Both are important to patients, since the former assesses a clinically relevant response from baseline (e.g. a 
Table 3. Reduction in individual nasal symptom scores by patient type

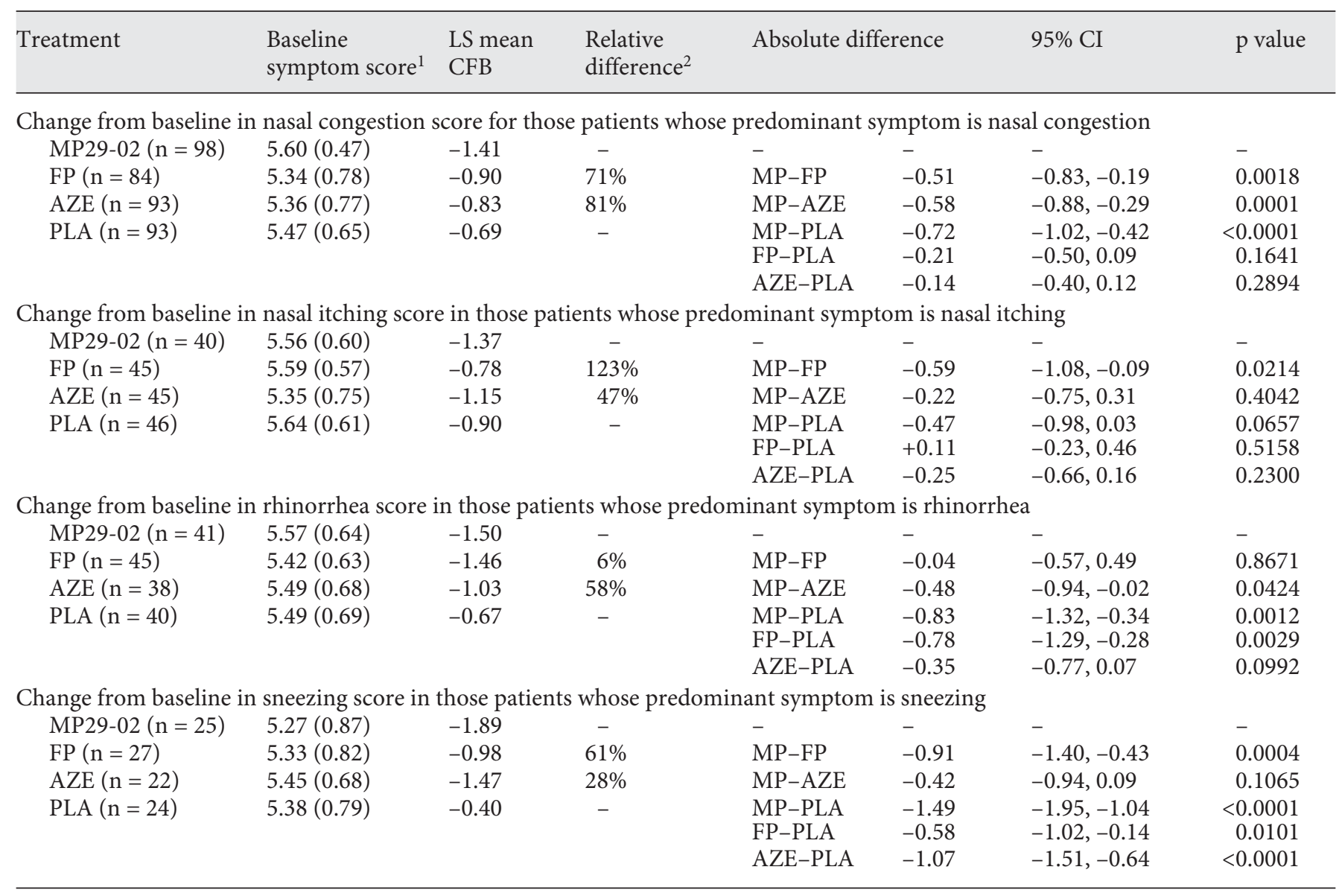

PLA = Placebo; $\mathrm{LS}=$ least squares CFB = change from baseline; $\mathrm{CI}=$ confidence interval.

${ }^{1}$ Mean (SD); maximum symptom score $=6$.

$2[1-($ FP or AZE - PLA $) /($ MP29-02 - PLA $)] \times 100$.

halving of symptom burden) and the later defines the symptoms remaining after treatment. Since clinical relevance is also influenced by patient-related factors such as disease severity, the predominant symptom and the presence of comorbidity, we also assessed efficacy in those patients with more and less severe disease, in those presenting with a predominant symptom, as well as the ability to treat the overall rhinitis symptom complex, incorporating the nasal and ocular symptoms most commonly associated with rhinoconjunctivitis. The only study to compare MP29-02 to commercially available active comparators was chosen to test these new efficacy analyses in order to ensure relevance to the real-world situation.

These analyses add important information not previously published [22]. A recent publication by Carr et al.
[23] on a different set of patients and using active comparators not commercially available also showed the treatment effect and consistent response of MP29-02 across seasons, symptoms and severity. However, treatment differences presented in that meta-analysis [23] were consistently less than those presented here, since the effect of formulation and device were eliminated.

Although the responder and other post hoc analyses reported here were not primary objectives of the trial, these parameters were defined as important by an independent panel of experts without having access to the data. The sensitivity analysis from $\geq 30$ to $\geq 90 \%$ rTNSS reduction from baseline incorporated a full range of improvement (from marginal to very important). One in 2 MP29-02 patients achieved the substantial response of 
halving their nasal symptom burden (i.e. $\geq 50 \%$ ) and 1 in 4 MP29-02 patients had mild or less symptoms after treatment (i.e. $\geq 75 \%$ reduction in rTNSS) achieved days faster than with either active comparator.

The analysis showed the significant advantage of MP29-02 over the most effective medication class currently available to treat AR (i.e. INS) and also the responder criterion at which INS cease to benefit patients over the placebo response (i.e. $\geq 60 \%$ rTNSS reduction from baseline). More MP29-02 patients also achieved the absolute response criterion of complete/near-to-complete nasal symptom resolution, which is clinically relevant considering both the severity of the patient population (i.e. rTNSS $\geq 8 / 12$ and nasal congestion $\geq 2 / 3$ ) and the strictness of the complete/near-to-complete criterion which means patients have less than mild symptoms across the rhinitis symptom complex spectrum. This was not the case with INS which did not differ from placebo in this regard.

In clinical practice, patients frequently present with a predominant symptom. Congestion is frequently reported as the most bothersome nasal symptom [15]. Not only was MP29-02 more effective than FP or AZE at providing targeted symptom relief per patient 'type' (e.g. more effectively reduced nasal congestion in patients whose predominant symptom was nasal congestion), it did so whilst maintaining overall control of the nasal symptom complex in all patient types. For nasal congestion-predominant patients, MP29-02 effectively reduced this symptom and patients' overall rTNSS, and thus may reduce the need for a nasal decongestant prior to MP29-02 administration.

However, for some patients the most bothersome symptoms of AR are from ocular origin [14, 17], which are usually less well controlled than nasal symptoms $[26$, 27]. Intranasal fluticasone furoate controls ocular symptoms [28], but its real efficacy compared to other INS is unclear since no head-to-head comparison has been made, and other INS also have some effect on these symptoms [29]. It cannot, therefore, be proposed that one INS is more effective than another. A novel treatment which more effectively controls ocular symptoms fills the gap for an important unmet need in AR. MP29-02 was clearly better at reducing ocular symptoms than FP and also AZE.

This clinical study did not include patients with mild $\mathrm{AR}$ who frequently self-medicate and are rarely seen in a clinic, but rather included patients with moderate-to-severe AR who represent the patient population most seen by GPs or respiratory specialists. The generalizability of these data is an inherent limitation of all randomized trials [30] since inclusion and exclusion criteria has to be in agreement with FDA and EMA guidelines. However, the results of FP are representative for the entire class of INS, since FP and fluticasone furoate [31] and FP and mometasone furoate [32] have shown comparable efficacy in direct comparison studies.

MP29-02 has an excellent safety profile. Data captured from 4,022 patients recruited into four 14-day SAR studies confirmed that treatment-related adverse events (TRAEs) observed were those usually reported with AZE (dysgeusia) and FP (headache and epistaxis), did not exceed placebo in many instances and were 'mild' in the vast majority of cases $[22,23]$. Furthermore, in a long-term (52-week) study in patients with chronic rhinitis the incidence of TRAEs was low, with no evidence of accumulation of TRAEs over time or evidence of cortisol suppression. Additionally, no nasal mucosal ulceration or perforations were seen and ocular examination findings were unremarkable [33].

MP29-02 also provided significant benefit over FP and AZE in reducing patients' global and individual nasal or ocular symptoms. The clinical benefit of MP29-02 was observed during the first day of assessment and was sustained over the entire course of treatment. This post hoc analysis may help physicians to better assess patients' phenotypes for treatment. Taken together, MP29-02 may be considered the drug of choice for moderate-to-severe AR patients. These measures could define a new standard for assessing clinical relevance in AR.

\section{Acknowledgements}

This study was funded by MedaPharma.

\section{References}

-1 Brozek JL, Bousquet J, Baena-Cagnani CE, Bonini S, Canonica GW, Casale TB, van Wijk RG, Ohta K, Zuberbier T, Schunemann HJ, Global Allergy and Asthma European Network, Grading of Recommendations Assessment, Development and Evaluation Working Group: Allergic Rhinitis and its Impact on Asthma (ARIA) guidelines: 2010 revision. J Allergy Clin Immunol 2010;126:466-476.

2 Canonica GW, Bousquet J, Mullol J, Scadding GK, Virchow JC: A survey of the burden of allergic rhinitis in Europe. Allergy 2007;62: $17-25$.

3 Schatz M: A survey of the burden of allergic rhinitis in the USA. Allergy 2007;62:9-16. 
4 Hellings PW, Fokkens WJ, Akdis C, Bachert C, Cingi C, Dietz de Loos D, Gevaert P, Hox V, Kalogjera L, Lund V, Mullol J, Papadopoulos NG, Passalacqua G, Rondon C, Scadding G, Timmermans $\mathrm{M}$, Toskala E, Zhang N, Bousquet J: Uncontrolled allergic rhinitis and chronic rhinosinusitis: where do we stand today? Allergy 2013;68:1-7.

-5 Bousquet J, Bachert C, Canonica GW, Casale TB, Cruz AA, Lockey RJ, Zuberbier T, Extended Global Allergy and Asthma European Network, World Allergy Organization and Allergic Rhinitis and its Impact on Asthma Study Group: Unmet needs in severe chronic upper airway disease (SCUAD). J Allergy Clin Immunol 2009;124:428-433.

-6 Meltzer EO, Gross GN, Katial R, Storms WW: Allergic rhinitis substantially impacts patient quality of life: findings from the Nasal Allergy Survey Assessing Limitation. J Fam Pract 2012;61:S5-S10.

-7 Walker S, Khan-Wasti S, Fletcher M, Cullinan P, Harris J, Sheikh A: Seasonal allergic rhinitis is associated with a detrimental effect on examination performance in United Kingdom teenagers: case-control study. J Allergy Clin Immunol 2007;120:381-387.

8 Vandenplas O, D’Alpaos V, Van Brussel P: Rhinitis and its impact on work. Curr Opin Allergy Clin Immunol 2008;8:145-149.

$\checkmark 9$ Hellgren J, Crevin A, Nordling S, Bergman A, Cardell LO: Allergic rhinitis and the common cold - high cost to society. Allergy 2010;65: 776-783.

10 Bousquet J, Khaltaev N, Cruz AA, Denburg J, Fokkens WJ, Togias A, et al: Allergic Rhinitis and its Impact on Asthma (ARIA) 2008 update (in collaboration with the World Health Organization, GA(2)LEN and AllerGen). Allergy 2008;63:8-160.

-11 Wallace DV, Dykewicz MS, Bernstein DI, Blessing-Moore J, Cox L, Khan DA, et al: The diagnosis and management of rhinitis: an updated practice parameter. J Allergy Clin Immunol 2008;122:S1-S84.

12 Valovirta E, Myrseth SE, Palkonen S: The voice of the patients: allergic rhinitis is not a trivial disease. Curr Opin Allergy Clin Immunol 2008;8:1-9.

-13 Marple BF, Fornadley JA, Patel AA, Fineman SM, Fromer L, Krouse JH, Lanier BQ, Penna $\mathrm{P}$, American Academy of Otolaryngic Allergy Working Group on Allergic Rhinitis: Keys to successful management of patients with allergic rhinitis: focus on patient confidence, compliance, and satisfaction. Otolaryngol Head Neck Surg 2007;136:S107-S124.
14 Virchow JC, Kay S, Demoly P, Mullol J, Canonica W, Higgins V: Impact of ocular symptoms on quality of life (QoL), work productivity and resource utilisation in allergic rhinitis patients - an observational, cross sectional study in four countries in Europe. J Med Econ 2011;14:305-314.

15 Stull DE, Schaefer M, Crespi S, Sandor DW: Relative strength of relationships of nasal congestion and ocular symptoms with sleep, mood and productivity. Curr Med Res Opin 2009;25:1785-1792.

16 Demoly P, Allaert FA, Lecasble M, PRAGMA: ERASM, a pharmacoepidemiologic survey on management of intermittent allergic rhinitis in everyday general practice in France. Allergy 2002;57:546-554.

17 Bousquet PJ, Demoly P, Devillier P, Mesbah $\mathrm{K}$, Bousquet J: Impact of allergic rhinitis symptoms on quality of life in primary care. Int Arch Allergy Immunol 2013;160:393-400.

18 Pitman R, Paracha N, Parker C, Acaster S, Bachert C, Bousquet J, Price D: Episode pattern and healthcare utilisation in patients with seasonal allergic rhinitis. Presented at EAACI, Geneva, June 16-20, 2012.

19 Snapinn SM, Jiang Q: Responder analyses and the assessment of a clinically relevant treatment effect. Trials 2007;8:31.

20 EMA guideline: Guideline on the clinical development of medicinal products for the treatment of allergic rhinoconjunctivitis. October 2004. http://www.ema.europa.eu/docs/ en_GB/document_library/Scientific_guideline/2009/09/WC500003554.pdf (accessed June 17, 2011).

21 US Department of Health and Human Services, Food and Drug Administration, Center for Drug Evaluation and Research, Center for Biologics Evaluation and Research, Center for Devices and Radiological Health: Guidance for industry - patient-reported outcome measures: use in medical product development to support labeling claims. December 2009. http://www.fda.gov/downloads/Drugs/GuidanceComplianceRegulatoryInformation/ Guidances/UCM193282.pdf (accessed November 28, 2012).

-22 Hampel FC, Ratner PH, Van Bavel J, Amar JJ, Daftary P, Wheeler W, Sacks H: Doubleblind, placebo-controlled study of azelastine and fluticasone in a single nasal spray delivery device. Ann Allergy Asthma Immunol 2010; 105:168-173.
23 Carr W, Bernstein J, Lieberman P, Meltzer E, Bachert C, Price D, Munzel U, Bousquet J: A novel intranasal therapy of azelastine with fluticasone for the treatment of allergic rhinitis. J Allergy Clin Immunol 2012;129:12821289.

24 Juniper EF, Guyatt GH: Development and testing of a new measure of health status for clinical trials in rhinoconjunctivitis. Clin Exp Allergy 1991;21:77-83.

25 Klossek JM, Annesi-Maesano I, Pribil C, Didier A: The burden associated with ocular symptoms in allergic rhinitis. Int Arch Allergy Immunol 2012;158:411-417.

26 Bousquet J, Lund VJ, Van Cauwenberg P, Bremard-Oury C, Mounedji N, Stevens MT, El-Akkad T: Implementation of guidelines for seasonal allergic rhinitis: a randomized controlled trial. Allergy 2003;58:733-741.

27 Bousquet J, Bodez T, Gehano P, Klossek JM, Liard F, Neukirch F, Le Gal M, Janin N, Allaf B: Implementation of guidelines for allergic rhinitis in specialist practices: a randomized pragmatic controlled trial. Int Arch Allergy Immunol 2009;150:75-82.

28 Rodrigo GJ, Neffen H: Efficacy of fluticasone furoate nasal spray vs. placebo for the treatment of ocular and nasal symptoms of allergic rhinitis: a systematic review. Clin Exp Allergy 2011;41:160-170.

29 Bielory L, Chun Y, Bielory BP, Canonica GW: Impact of mometasone furoate nasal spray on individual ocular symptoms of allergic rhinitis: a meta-analysis. Allergy 2011;66:686-693.

- 30 Costa DJ, Amouyal M, Lambert P, Ryan D, Schunemann HJ, Daures JP, Bousquet J, Bousquet PJ, Languedoc-Roussillon Teaching General Practitioners Group: How representative are clinical study patients with allergic rhinitis in primary care? J Allergy Clin Immunol 2011;127:920-926.

31 Okubo K, Nakashima M, Miyake N, Komatsubara M, Okuda M: Comparison of fluticasone furoate and fluticasone propionate for the treatment of Japanese cedar pollinosis. Allergy Asthma Proc 2009;30:84-94.

32 Mandl M, Molop K, Lutsky BN: Comparison of once daily mometasone furoate (Nasonex) and fluticasone propionate aqueous nasal sprays for the treatment of perennial rhinitis: 194-079 Study Group. Ann Allergy Asthma Immunol 1997;79:370-378.

33 Price D, Bousquet J, Helling P, Scadding G, Fokkens W, Munzel U, Bachert C: Short and long-term safety of MP29-02*: a new therapy for the treatment of allergic rhinitis. Presented at SERIN congress, Leuven, Belgium, March 21-23, 2013. 